\title{
Traditional Ecological Knowledge for Climate Change Assessment and Rainfall Prediction: A Case of Adami Tulu Jido Kombolcha District, Oromia Region, Ethiopia
}

\author{
Martha Kidemu ${ }^{1,2, *}$, Martha Gebreyesus ${ }^{1}$, Mihiret Semere ${ }^{1}$, Adefires Worku ${ }^{1}$, Agena Anjulo ${ }^{1}$ \\ ${ }^{1}$ Climate Change Research, Ethiopian Environment and Forest Research Institute (EEFRI), Addis Ababa, Ethiopia \\ ${ }^{2}$ African Center of Excellence for Climate Smart Agriculture and Biodiversity Conservation, Haramaya University, Dire Dawa, Ethiopia \\ Email address: \\ maarsiiftokkoo@gmail.com (M. Kidemu),mgebryesus@yahoo.com (M. Gebreyesus), smihert@gmail.com (M. Semere), \\ adefiresworku2012@gmail.com (A. Worku), agenaanj@yahoo.com (A. Anjulo) \\ ${ }^{*}$ Corresponding author
}

\section{To cite this article:}

Martha Kidemu, Martha Gebreyesus, Mihiret Semere, Adefires Worku, Agena Anjulo. Traditional Ecological Knowledge for Climate Change Assessment and Rainfall Prediction: A Case of Adami Tulu Jido Kombolcha District, Oromia Region, Ethiopia. International Journal of Natural Resource Ecology and Management. Vol. 5, No. 2, 2020, pp. 43-48. doi: 10.11648/j.ijnrem.20200502.12

Received: March 14, 2020; Accepted: March 27, 2020; Published: April 17, 2020

\begin{abstract}
Data on environmental problems of the area, local manifestations of climate change, climate change coping strategies, rainfall prediction mechanisms and their threats were collected in three systematically selected administrative units of the study area using focus group discussion, key informant interview and household (HH) survey from May to June, 2017. Focus group (FG) discussion that participate youth, elders, women, religion and tradition leaders and experts with average members of 15 was organized at each administrative units. Sample key informants (KI) were selected by the focus group members by setting criteria to get deep information. HH survey was conducted from randomly selected 92 HHs samples determined by Kothari (2004). Qualitative data analysis method was used to summarize the information. Results showed that environmental problems in the area are directly or indirectly related to climate. And the communities rely on their indigenous rainfall prediction using meteorological, astronomic and animal behavioral indicators. The main indicators are: wind direction, appearance and shape of cloud, star pattern, moon's appearance, cattle behavior, chirping of bird, bee's migration, and color of lake and appearance of rainbow. The study also depicted that most $(85 \%)$ of the communities heavily rely on the indigenous knowledge for planning agricultural activities or early warnings for preparedness. However, it has been threatened due to critics by religious people, lack of trust of young generation, degradation of the indicators and lack of documentation. There is need for careful evaluation and enhancement for social-ecological resilience of the vulnerable communities.
\end{abstract}

Keywords: TEK, Indigenous Knowledge, Rainfall Prediction, Climate Change, Indicators

\section{Introduction}

Climate change has become the major environmental challenges the world is facing today. Although climate change affects the whole world, its impact is substantial in least developed countries. The major impacts include frequent and severe droughts, flood, increased pests and diseases, damage on crops and livestock, loss of biodiversity and decline in ecosystem productivity, resulting in households' welfare depletion, massive migration and competition of rural communities for scarce resources [1]. Climate change adaptation and mitigation are globally known responses to adverse effects of climate change.

The terms indigenous, traditional and/or local knowledge refers to knowledge and know-how that is accumulated through experience and guides human societies in their interactions with their surrounding environment. Traditional Ecological Knowledge (TEK) refers to the evolving knowledge acquired by indigenous and local people over hundreds or thousands of years through direct contact with the environment [2]. Although it was forgotten due to industrialization, recently it was recognized mainly in areas of natural resource management, climate change adaptation and mitigation, biodiversity conservation and weather forecast [2, 3]. 
It was only recently that the issue of traditional ecological knowledge (TEK) has emerged in IPCC in its fourth assessment report. It was stated that TEK is "an invaluable basis for developing adaptation and natural resource management strategies in response to environmental and other forms of change" [4]. It was also recognized that TEK system plays important role in short and medium-term weather forecasting [5]. Although integrating TEK system in formal climate change adaptation plans are very slow, there are some efforts [6-8] done in different parts of the world, although this was never done in Ethiopia. There are a few studies that show the application of TEK system to climate initiatives in rural Ethiopia. For instance, in Ethiopia, as assessed [9] on the indigenous biotic weather forecasting system in Borena herders in southern Ethiopia showed to support their livelihood. Similarly, community climate change coping mechanisms in southern Ethiopia was studied to have crucial role in sustaining their livelihood [10].

The purpose of this study was, therefore, to assess local climate change manifestations and evaluate the indigenous rainfall prediction mechanisms in Adami Tulu Jido Kombolcha District by way of identifying and analyzing local indicators used in rainfall prediction in selected administrative units.

\section{Theoretical Background}

Ethiopia is the second-most populous country in Sub-Saharan Africa with an estimated population of over 100 million, most of $(80 \%)$ of whom live in rural areas [11]. The country has diverse topography, with elevations ranging from $126 \mathrm{~m}$ below sea level to mountains above 4,500 m. Associated with this, there is variety of climate ranging from equatorial rainforest in the southern part, to desert-like conditions in the northeast part of the country. Central Rift Valley (CRV) is one of the environmentally vulnerable regions in Ethiopia, where rain fed crop production has expanded rapidly over recent decades [12]. In this region, the existing scarcity of rainfall has been aggravated by climate change; affecting crop production by raising the evaporative demand [12].

Adami Tulu Jido kombolcha destrict, is located in the heart of CRV, Southwest of Lake Ziway at altitude of 1500-2300 m a.s.1. According to traditional agro-climatic zone classification, its climate falls under semi-arid [13]. The annual rain fall varies from $600-800 \mathrm{~mm}$ and it is characterized by bimodal rainfall. There is a very short and unreliable rain during the months April-May, while most of the rain occurs during three months (June-August) and sometimes up to September. However, the pattern of rainfall is usually erratic with fluctuations in the start and end of the season, to total absence of rainfall at times [14].

According to the district's Agricultural Office, much of the population depends on subsistence mixed farming of livestock and crop production. There are also many rural households engaged in collecting and selling forest products from natural forest. The people in the distric are Oromo in ethnic group having different clan such as 'Wege','Abure', 'Kontoma', 'Habelose' and 'Koji' in local language. Lack of climate information is one of the challenges of farmers in the country and particularly in the area to make appropriate decision on agricultural activities. For these reasons, rural communities in the area are known to rely to a greater extent on their indigenous or traditional ecological knowledge system in their day-to-day livelihoods.

\section{Methods}

\subsection{Sampling}

Three smallest administrative units in a district called Kebele Administrative units (KAs) were systematically selected from the district to represent agroecologies in the study area which is for data collection. One focus group discussion (FGD) with average members of 15 was organized at each Kebele. The members were selected to include youth, elders, women, religion and tradition leaders and experts with participation of KA administrator. Sample key informants (KI) were selected by the focus group members by setting criteria's like; who dwelled in the area for more than 20 years, whose livelihood is agriculture, who participate in social mechanisms and who have known to have full of knowledge on traditional weather forecasting. Using the criteria, 10 to 15 individuals were purposively selected from each KAs for the KI interview. For Household (HH) survey, HH sample size was determined by Kothari sample size determination method [15]. Accordingly, 19, 41 and 32 sample $\mathrm{HHs}$ was randomly selected from each of the three KAs: Haroresa kalbo, Abine Germama and Galo Hirape respectively to administer questionnaire to total of $92 \mathrm{HHs}$.

\subsection{Data Source and Collection Method}

Data was collected on following topics: existing environmental problems in the area, local manifestations of climate change and vulnerabilities, coping strategies, community rainfall prediction mechanisms, how community-based indicators supported their livelihoods and potential threats to these knowledge systems. A guding questions on the topics was employed to collect data using FG discussion and KI interview. Key informant interview was conducted particularly to get deep information on indigenous climate prediction indicators and their meanings. Data on socioeconomic characteristic of individual $\mathrm{HH}$ and the source of rainfall prediction the $\mathrm{HH}$ depend mostly for agricultural activities decision making were collected using HH survey.

\subsection{Data Analysis}

Data collected by FG discussion and KI interview was analysed by thematic analysis method of analyzing qualitative data. Particularly data on the rainfall prediction meachanisms were summarized, classified and described to make it understandable. Data from household survey analyses was conducted using descriptive statistics by Statistical Package 
for Social Science (SPSS).

\section{Result and Discussion}

\subsection{Background and Socioeconomic Information}

The majority of respondents are Oromoo ethnic group, 55\% of them which were in 'Wage' clan group. Background of the respondents is summarized in Table 1. The target farmers' community literacy level is very low (Table 1). Thirty fife percent of the $\mathrm{HH}(35 \%)$ were illiterate or never went to school and fourty four percent (44\%) joined adult education called 'golmasa timirt' in local language which was given during Derg Regime to teach reading and writing in local languag. Only ten percent (10\%) of the joined high school and none went to college or University. Average family size is 9 . Since the area is Muslim religion dominated, one man can marry up to seven women. Most (98\%) of the respondents have land of their own. Mixed crop-livestock farming system is common in the area. Seventy eight percent (78\%) of the respondents' real livestock like Horse, donkey, cattle, sheep, goat and poultry are reared in the area. Ox is used for ploughing land in addition to being used for meat consumption. Common crops cultivated are maize, teff and barley while chicken pea and wheat are rarely cultivated.

Table 1. Background of the respondents (HH survey).

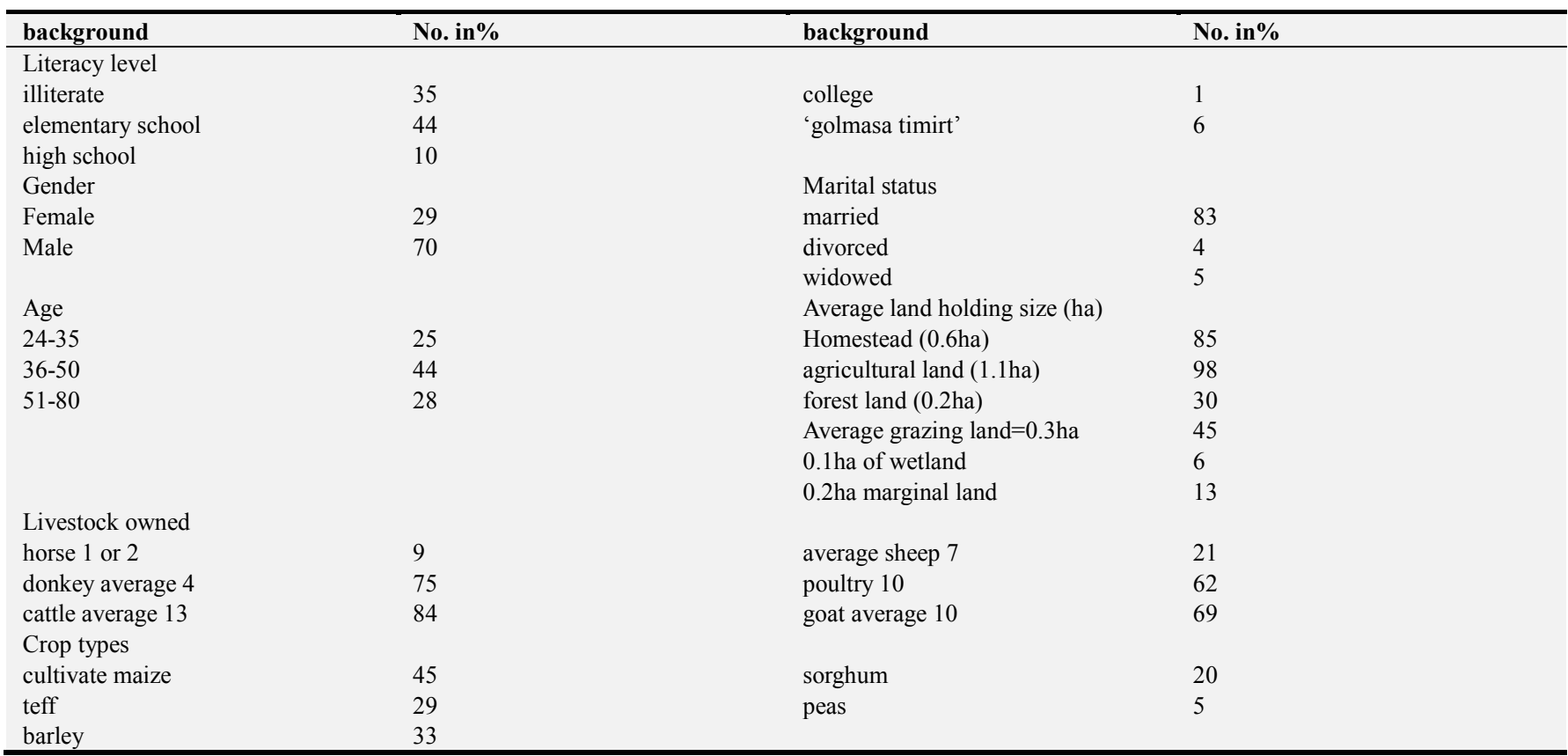

Summary of average land holding size showed that eighty five percent ( $85 \%$ ) of the respondents own 0.6 ha of homestead, $98 \%$ own 1.1 ha of agricultural land other than homsted, and only $30 \%$ own 0.2 ha of forest land. The smaller number of $\mathrm{HH}$ who own forest land may be because forest land is mostly under communal ownership. An average 0.3 ha of grazing land is owned by $45 \%$ of the respondents. Only $6 \%$ of the respondents own 0.1 ha of wetland and $13 \%$ own 0.2 ha marginal land. Wetland according to the farmers is land near river or waterlogged land and marginal land is degraded land that no more give productivity.

The HH survey result showed that $85 \%$ of the respondents heavily rely on indigenous rainfall prediction for agricultural activities decision making.

\subsection{Environmental Problems}

As mentioned by the respondents, frequent flood and drought incidences, rainfall variability, livestock and crop diseases, intensive winds that damage crop, landslides, soil erosion, and shrinkage of wetlands, deforestation and local extinction and or scarcity of some tree species were identified as the most important environmental challenges at the study area. Forests were cleared for farm land expansion, which is derived by fast growing population in the area and unfavourable weather condition for agricultural productivity. Farmers clear forest land with the intention of farm area expansion for new and fertile land to compensate declining agricultural productivity caused by loss of soil fertility, frequent drought and rain fall variability and the overall increasing livelihood vulnerability and poverty. These show recent increase of dependence on forests as alternative means of income by selling fuel wood and charcoal. These on the other hand enhanced severe degradation of the Acacia woodlands and wooded grasslands.

Livestock asset is declining mainly due to scarcity of forage and drinking water. As far as water availability is concerned, the participants mentioned that, their established tradition of collecting enough water in the morning after rains in the night was not any more possible. This among others is due to increased temperature that facilitates quick loss of water through evapotranspiration. Rain water is also lost immediately to erosion as soils have poor water infiltration 
capacity where vegetation cover is lost. These have resulted in increased competition for water at the study area. The competition is further aggravated by increased interest in diversion of scarce water for irrigation by factories at the study areas. Respondents emphasized their serious concern about continued reduction of the local lake water resource, locally called 'haro', mainly due to unwise use of water for irrigation by the growing number of factories since recently, in addition to siltation problem due to soil erosion from upstream. Therefore, despite the fact that there are socio-economic, policy and institutional problems in the area; environmental problems, mainly those related to climate change were the main factors of social-ecological vulnerability at the study areas.

\subsection{Local Climate Change Manifestations and Vulnerability}

Communities explain climate change mainly by: changes in length of season, based on rainfall sufficiency for crop and forage production or rainfall variability in terms of its impact on environment like land slide and soil erosion. According to one of the key informants, the areas were used to get rain for more than six months and four to seven days a week, but currently the dry season has extended from four to 10 months and it may rain for one day per week or not at all even during rainy seasons. One respondent mentioned the current situation by saying "current rain has no brother" to mean, rain is erratic, or it rains after the soil and vegetation have already become dry. They also emphasized that rainy season is no more predictable and there is mix of dry and wet seasons. Respondents also explained shift in the rain fall onset, for instance, they mention that, 30 years ago rain used to start in March and end in September. Currently, it is not even known; it may start between May and June or may not rain at all. In addition, late coming rainfall often causes flood and run off when it rains, resulting in low infiltration and low soil moisture that is not enough to grow crops and forage.

The study area communities relate forest degradation to effets of climate change that changes rainfall and temperature. It was mentioned that forest has become vulnerable to climate change directly due to lack of sufficient rainfalls and indirectly due to deforestation for copping up the loss of crop and livestock productivity. The communities listed (in local names) some of the common plant species currently disappeared and or endangered due to drought and deforestation: 'Ejersa', 'Tatesa', 'Wadesa', 'Hindesa', 'Badesa', 'Mancera'(source of food), 'Garbi' (cultural spiritual prayer place), 'Habile', 'Kurkura' and 'Gunaa'. Most of these species were known to be sources of timber, fuel wood, fruits/food and livestock and bee fodder, among others. According to most of respondents, most of these species are unable to regenerate after cutting or from soil seed bank or once they regenerate the seedlings are unable to adapt to increased dry spell.

The change in rainfall amount was explained in terms of its inadequacy for crop, forage and forest productivity as well as by the availability of water for livestock. Crop and livestock yields are related with rainfall amount. Accordingly, there might be low yield or total absence of yield depending on rainfall sufficiency.

Due to differentiated responsibilities between men and women, there are differences in expressing the impacts. Since women are responsible for ensuring household food security, they use additional terms to explain local manifestation of climate change and its impact in their livelihoods. Women in the focus group particularly mentioned the challenges girls face to fetch water and fire wood. They stated that, in some areas, girls have to leave at $5 \mathrm{am}$ in the morning to find water point and may comeback home at $2 \mathrm{pm}$ in the afternoon. This added to other factors has been undermining girl's education at the area. Women headed households in particular are victims of climate change as they are unable to produce enough to feed their families under current frequent drought and unpredictable rainfall, worsening existing food insecurity conditions. Since women are charged with securing various livelihood means such as water, food and fuel for cooking, as climate change intensify; they face the greatest challenges to fulfill their responsibilities [16].

\subsection{Indigenous Coping Strategies}

Indigenous practices identified as means of coping to climate change include planting trees and protecting existing patch forest, farming near and along river/lake banks, crop diversification, change in crop planting dates, migration to wetter area, collecting crop residue for livestock feeding, collection and sale of forest products and the like. In addition, the indigenous people practice various activities to restore degraded landscapes by way of collecting and spreading cattle dung on their farm lands and by constructing animal/cattle stall in marginal land for rehabilitation. They also dig shallow wells to collect water for dry seasons. They also request support from relatives, borrow and/or share goods and services from each other during bad seasons. Other coping mechanisms include requesting local government for supplementary food aid, selling livestock such as goat and poultry to buy food, saving food and cash, migration to town for search of daily job, reducing food consumption, and selling of forest products such as fuel wood and charcoal.

\subsection{Community Rainfall Prediction Mechanisms}

The study area communities use various indicators in their environment to predict the onset of rains and to identify the season's suitability for agricultural decision making (Table 2). They predict the coming of rainfall on daily and predict season's condition if it is bad or good. According to their expression, bad season means a season with drought or flood; whereas good season is a season which has optimum rain for crop, grass or forage production. Communities' prediction of rainfall for shorter period mostly at the beginning of cropping season is applied for land preparation, while seasonal prediction is applied to plan for a crop type and/or for preparedness to save food for the coming season.

The TEK rainfall prediction indicators include meteorological (wind, cloud, tornado and lightning), 
astronomical (moon, sun and star), animal behavior (frog and cattle) and other environmental indicators (Table 2). Communities observe the direction of cloud and expect rain if it is from the southern direction. In addition, they believe that not all types of clouds bring rain. They explain this as: when the cloud has a shape as they explain in local language as 'botole' 'botole' means seen one over another, rain is expected.
They also observe the color of sunrise and if it is red, rain is expected. In addition if weather is hotter, they predict that it is going to rain soon. They also stated that, they used to observe tree phenology to predict rainfall. They stated that flowering of a tree locally called 'harbu', which is now extinct, was an indication of coming of rain.

Table 2. Rainfall prediction indicators.

\begin{tabular}{|c|c|}
\hline Indicators for short time forecast & Indicators for season's quality \\
\hline $\begin{array}{l}\text { 1. wind direction (south to North) } \\
\text { 2. presence of cloud and less windy, } \\
\text { 3. hiding of moon at night, } \\
\text { 4. presence of small tornado locally called }\end{array}$ & $\begin{array}{l}\text { 'Good' rainy season indicators: } \\
\text { 1. moon's half side directs north, } \\
\text { 2. color of water/lake become black, } \\
\text { 3. bees migrate to land, } \\
\text { 4. at the onset of rain if it rains at morning and night }\end{array}$ \\
\hline $\begin{array}{l}\text { 'habombolesa' } \\
5 \text { when the color of sun become red in the morning } \\
6 \text { coming of rain in nearby areas (from south direction), } \\
7 \text { Star become bigger and many (rain is expected in } 28 \text { days), } \\
8 \text { cattle smelling behavio, } \\
9 \text { a bird's song local called 'humo' is heard } \\
10 \text { frog croak (lauder) }\end{array}$ & $\begin{array}{l}\text { 'Bad' season indicators } \\
\text { 1. moon half side direct upward } \\
\text { 2. rainbow appearance } \\
\text { 3. cattle behavior (not interested to graze and drink, refuse to get out and in) } \\
\text { 4. bees migrate to river } \\
\text { 5. at the onset of rain if it rains in noon }\end{array}$ \\
\hline
\end{tabular}

There are also other season quality indicators in addition to what was listed in Table 2. Community forecast good and bad season by social indicators by observing on which day the rain is starts to rain. The days are named by people believed to have spiritual power. Accordingly the names given, if it rains on 'ayana' in local language to mean fortune of women day, then it is interpreted to be kind and good rainy season is expected. If it rains on 'ayana' of horse, then the rain is expected to be erratic and poor crop production is expected in the coming season. If it rains on 'ayana' of elephant, heavy rain is expected. Other social indicators identified were coffee spoiling and unusual cry of children for food indicated the coming season to be bad.

There are similar situations in other parts of Africa. Rural communities realized that some animals, birds, insects and plants had the capacity to detect and respond to changes in atmospheric conditions. They also observed the positions of stars, the sun and the moon, the wind strength and direction and the cloud position and movement are used to predict rainfall [6]. Indigenous knowledge system use different indicators to predict the quality of the season before the onset of the rains, using climate indictors including birds, wild fruits, trees and worms [7]. The behavior of animals such as livestock, birds, insects and amphibians is also used by farmers to predict the onset of the rainy season in Africa [8]. According to the authors, the songs and movements of different birds was known to be an indication of the onset of rains as it has been reported in Mali, Nigeria, Swaziland, Tanzania and Zimbabwe, among other countries in SSA.

In spite of the fact that the indigenous communities are almost dependent on TEK of rainfall prediction information, there are potential constraints or threats to it. The constraints listed by the respondents were religious people criticize; those who don't accept such method believe that, those who predict rain are witchcrafts and rather trust that rain is from God. There is also lack of trust among young generations due to 'modernization'. The young perceived the knowledge to be 'traditional' or passive and ignore the information. In addition, environmental degradation due to, among others, climate change or deforestation etc has caused loss of various indigenous rainfall prediction indicators. Other constrain is absence of documentation to pass it from generation to generation.

\section{Conclusions}

The study showed that the community heavily relies on their indigenous prediction methods. Therefore careful investigation of the correlation of prediction mechanisms with scientific implication for integration with scientific rainfall prediction is crucial to improve resilience to impacts of climate change. This in addition supports scientific forecasts as it enhances accuracy which tend to decrease with decreasing area under consideration. In addition, local forecast improve access to climate information in rural areas, where there is no or scarce infrastructure. The lack of trust among the community showed the need of detail study and awareness creation among young generations. Sharing experience of other Africa country that has advanced in using TEK by integrating with scientific prediction is very important. Finally climate change is expected to worsen the existing weather hazards, in addition to be the cause for extinction of the TEK indictors. This strongly suggests further research to understand how the future climate unfolds and affect the local farmer's livelihoods, and identify and strengthen community based prediction methods.

\section{Acknowledgements}

We would like to thank the smallholder farmers who participated and freely shared their wealth of indigenous knowledge on climate change that has been used in this study. 
In addition we thank staffs in study areas' Agricultural and Disaster Risk Management office of the study area. Finally, we are grateful to Socio-economics, Policy, Extension and Gender Research Directorate staff of Ethiopian Environment and Forest Research Institute for their comments in questionnaire preparation.

\section{References}

[1] I. Abaje and P. Giwa, "Management of Dry Forests for Social-ecological Resilience of the Pastoral and Agro-pastoral Communities in the Dry Zone of Ethiopia. Dissertation: Technology University of Dresden, Faculty of Environmental Sciences, Germany," in Urban Flooding and Environmental Safety: A Case Study of Kafanchan Town in Kaduna State. A Paper Presented at the Golden Jubilee (50th Anniversary) and 49th Annual Conference of the Association of Nigerian Geographers (ANG) Scheduled for 15th - 19th Octob, 2007.

[2] C. Folke, "Resilience: The emergence of a perspective for social-ecological systems analyses," Glob. Environ. Chang., vol. 16, no. 3, pp. 253-267, 2006.

[3] W. Adefires, "Management of Dry Forests for Social-ecological Resilience of the Pastoral and Agro-pastoral Communities in the Dry Zone of Ethiopia. Dissertation: Technology University of Dresden, Faculty of Environmental Sciences, Germany.”

[4] G. Raygorodetsky, "Why traditional knowledge holds the key to climate change. United Nations University," 2011..

[5] J. A. Parrota and M. Agnoletti, Traditional Forest-Related Knowledge and Climate Change, vol. 12, no. 2. 2012.

[6] C. M. Enock, "Indigenous Knowledge Systems and Modern Weather Forecasting: Exploring the Linkages," J. Agric. Sustain., vol. 2, no. 1, pp. 98-141, 2013.
[7] G. Soropa, S. Gwatibaya, K. Musiyiwa, F. Rusere, G. A. Mavima, and P. Kasasa, "Indigenous knowledge system weather forecasts as a climate change adaptation strategy in smallholder farming systems of Zimbabwe: Case study of Murehwa, Tsholotsho and Chiredzi districts," African J. Agric. Res., vol. 10, no. 10, pp. 1067-1075, 2015.

[8] P. Mafongoya, Indigenous knowledge systems and climate change management in Africa, no. November. 2017.

[9] A. Y. Dasalegn, D. Solomon, J. Yangi, J. Recha, and M. Radeny, "Opportunities and challenges of indigenous biotic weather forecasting among the Borena herders of southern Ethiopia," Springerplus, vol. 4, no. 1, 2015.

[10] T. Abate, "Contribution of Indigenous Knowledge to Climate Change and Adaptation Response in Southern Ethiopia," J. Earth Sci. Clim. Change, vol. 7, no. 11, 2016.

[11] E. I. Team and I. Aid, "ETHIOPIA CLIMATE ACTION REPORT FOR 2016," 2017.

[12] T. Gemechu, "Earth Science \& Climatic Change Impact of Climatological Parameters on Crop Water Use of Maize and Sorghum : A Case of Adami-Tulu Jido-Kombolcha woreda, Central Rift," vol. 7, no. 10, 2016.

[13] T. Abera, Z. Mohammed, and M. Bekele, "Local People Perception on the Role of Area Exclosure in the Central Rift Valley of Ethiopia : a Case Study at," Int. J. Sci. Res. Publ., vol. 6 , no. 10 , pp. 583-594, 2016.

[14] A. M. Program, "Socio-ecological Functioning and Economic Performance of Rain-fed farming Systems in Adami Tulu Jido Kombolcha District, Ethiopia Norwegian University of Life Sciences," no. February, 2008. Kothari, "Sampling and Sampling Technique," 2004.

[15] UNDP, "Overview of linkages between gender and climate change Policy brief found at http://www.undp.org/content/dam/undp/library/gender/Gender $\% 20$ and\%20Environment/PB1-AP-Overview-Gender-and-cli mate-change.pdf," 2013. 